\title{
Screening for lung cancer: A review
}

\author{
B E Schär, MB ChB, FCP SA, Cert Pulm SA Phys \\ Pulmonologist, Mediclinic Midstream, Centurion, Gauteng
}

Corresponding author: B E Schär (bronwyn.schar@mediclinicnetwork.com)

\begin{abstract}
Lung cancer (LC) is the leading cause of cancer-related death worldwide. Its overall poor prognosis is attributable to the fact that most patients remain asymptomatic until the disease is advanced and, therefore, present with late-stage incurable disease. The rationale for LC screening is that early detection of asymptomatic disease offers the opportunity for earlier intervention, at a stage when definitive cure is still feasible, which has the potential to reduce LC-related mortality and morbidity. The findings of the National Lung Screening Trial provided the first strong evidence in support of this rationale. Since its publication, several professional organisations and societies have developed guidelines recommending the implementation of LC screening with low-dose computed tomography in asymptomatic, high-risk individuals. Although the benefits of such screening programmes may be significant, they must be carefully weighed against the potential harms to the relatively large number of healthy individuals who would undergo screening. This review examines the available evidence and current recommendations for LC screening, including benefits, potentials harms and requirements for implementation of a high-quality, safe and effective programme. In addition, the costs and availability of LC screening programmes in both the global and local settings are considered.
\end{abstract}

S Afr Respir J 2015;21(4):101-107. DOI:10.7196/SARJ.2015.v21i4.37

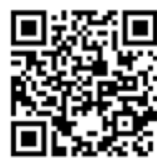

Lung cancer (LC) is a common malignancy among men and women; an estimated 1.8 million new cases were reported worldwide in the year 2012, 58\% of which occurred in the developing world. ${ }^{[1]}$ It is the leading cause of cancer-related deaths, and although its incidence is similar to other common malignancies (including breast, prostate and colorectal cancer), it causes four times as many deaths..$^{[2,3]}$ In 2012, LC-associated deaths accounted for $19.4 \%$ of global cancer mortality. ${ }^{[1]}$ Similarly, LC mortality has been reported to account for $17 \%$ of cancer-related deaths in South Africa (SA). ${ }^{[4]}$

The 5-year survival rate for LC remains low (16.8\%) despite advances in therapy. ${ }^{[5]}$ The stage of non-small-cell LC (NSCLC) at the time of diagnosis determines prognosis. Since stage I NSCLC can be treated, and potentially cured with surgical resection, the 5 -year survival rate is significantly better than for stage IV disease $(60 \%$ v. $<5 \%) .{ }^{[5]}$ Furthermore, smaller tumours within stage I NSCLC correlate with improved clinical outcomes. ${ }^{[6,7]}$ Although data for small-cell LC (SCLC) are limited, they also support improved prognosis in individuals diagnosed with early-stage disease. ${ }^{[8]}$ The overall poor prognosis of LC is largely attributable to the fact that $75 \%$ of patients present with late-stage, inoperable disease. ${ }^{[9,10]}$ The reported operability rate in SA literature is $10-11 \%$, indicating that the proportion of patients who present with curable disease is even lower than that described internationally. ${ }^{[4,11]}$

The rationale for LC screening is that early detection and treatment of asymptomatic LCs has the potential to reduce LC-related mortality and morbidity by increasing the overall cure rate, allowing more limited surgical resection in order to achieve cure and reducing exposure to adjuvant therapies. ${ }^{[8,12]}$ The utility of sputum cytology and chest radiography (CXR) alone, or in combination, as LC screening tools has been extensively studied and no benefit has been demonstrated for either modality. ${ }^{[13,14]}$ Previously, several single-arm studies suggested that screening with low-dose computed tomography (LDCT) may be beneficial, ${ }^{[15]}$ but the 2010 publication of the National Lung Screening Trial (NLST) provided the first strong supporting evidence for LC screening with LDCT. ${ }^{[16]}$ This led various medical professional societies, clinical networks and the US Preventative Services Task Force (USPSTF) to make recommendations in support of LC screening with LDCT in high-risk individuals. ${ }^{[12,17-19]}$ Subsequently, additional studies were done that have better defined which individuals are at highest risk and are most likely to benefit from LC screening. ${ }^{[20-22]}$

Several characteristics of LC, together with available evidence, suggest that implementation of LC screening may be both feasible and beneficial. ${ }^{[12,17,23,24]}$ This review examines current recommendations for LC screening, including benefits, potential harm and consideration of costs and availability of screening programmes.

\section{Screening with LDCT}

Since 2000, a number of cohort and randomised controlled trials (RCTs) have been performed to evaluate the utility of LDCT compared with CXR or usual care. Table 1 provides a list of select RCTs and highlights the differences in their respective inclusion criteria, screening intervals and definitions for positive screen results. ${ }^{[25-31]}$ Since the ultimate objective of screening is to identify and treat early-stage LC, the participants' fitness for lung surgery is an important factor to consider when assessing eligibility for screening. ${ }^{[12]}$ Accordingly, it is noteworthy that all the trials listed excluded those individuals with comorbidities that precluded them from curative LC surgery. In addition, some required participants to demonstrate a specified baseline effort tolerance before undergoing screening. ${ }^{[27]}$

The NLST is the largest RCT of LC screening to date. The study included 53454 men and women at 33 tertiary centres across the USA. Individuals were considered high risk and eligible for screening if they were between the ages of 55 and 74 years, had a smoking history of at least 30 pack-years, and were either current cigarette smokers or had quit smoking within the past 15 years. Participants were randomised to LC screening with either LDCT or CXR annually for 3 years, with a median duration of follow-up of 6.5 years. Any noncalcified nodule measuring $\geq 4 \mathrm{~mm}$ in diameter identified on LDCT 
or CXR was classified as a positive screen. Of the studies performed, $24.2 \%$ of LDCTs and $6.9 \%$ of radiographs were positive, with $39 \%$ of individuals in the LDCT group and 16\% of those in the radiograph group having at least one positive screen during the 3-year period. Of these abnormalities $96.4 \%$ were false-positive findings (i.e. they did not lead to a diagnosis of cancer). Although most positive findings were resolved by further imaging, $11 \%$ were followed by an invasive diagnostic procedure. The rate of procedure-related complications was low (1.4\% of positive screenees in the LDCT group and $1.6 \%$ of those in the CXR group experienced a complication). The trial was stopped prematurely as an interim analysis demonstrated a statistically significant reduction of $20 \%$ in LC-specific mortality and $6.7 \%$ in allcause mortality in the LDCT arm. The number needed to screen with LDCT to avoid one LC death was 320. ${ }^{[16]}$

The ongoing Nederlands-Leuven Longkanker Screenings Network (NELSON) trial, which compares LDCT screening (at 1,2 and 2.5 years) with no screening, is the second largest of the RCTs and is powered to detect a $25 \%$ decrease in LC mortality after 10 years. ${ }^{[30]}$ The data from this trial will be pooled with those from the Danish LC Screening Trial before being published. ${ }^{[27]}$ Unlike many of the other RCTs, the NELSON trial uses volumetric measurements to assess screen-detected nodules. This approach appears to be more specific than measurement of diameter and has a significantly lower positive screen rate $(2.6 \%$ and $1.8 \%$, respectively, in screening rounds 1 and 2), compared with the $26.4 \%$ across all rounds of screening in the NLST. ${ }^{[16,31]}$ Although not yet included in any published practice guidelines, the results from the NELSON trial suggest that the use of a volumetric strategy offers the potential advantage of decreasing the number of follow-up examinations needed for participants with a positive screen result. ${ }^{[31]}$

\section{Recommendations for screening with LDCT}

Pursuant to the findings of the NLST, several professional societies have published LC screening guidelines (Table 2). Most have defined eligibility for screening based on the NLST inclusion criteria and have advocated a screening process that closely mirrors that followed in the NLST. Based on the systematic review of the benefits and harmful effects of LDCT screening, published by Bach et al., ${ }^{[18]}$ the American College of Chest Physicians published clinical practice guidelines that recommend LC screening only for individuals who meet NLST inclusion criteria and have access to treatment in a multidisciplinary centre capable of delivering comprehensive cancer care commensurate with that provided in the NLST. ${ }^{[17]}$

The American Cancer Society (ACS) guidelines support screening in a similarly defined high-risk population, with the proviso that screened individuals should be in good health. ${ }^{[32]}$

The USPSTF recommendation statement, published in 2014, supported LDCT screening for adults aged 55 - 80 years who have a $\geq 30$ pack-year cigarette smoking history, and either smoke currently or quit smoking within the past 15 years. ${ }^{[1]}$ The decision to extend the age range beyond that of the NLST (ages 55 - 74 years) was based on the outcomes of a statistical comparative modelling study conducted by de Koning et al., ${ }^{[22]}$ which suggested that continuation of annual screening until the age of 80 years would be advantageous. The caveat stated by the USPSTF is that screening should be discontinued either once an individual develops a health problem that substantially limits their life expectancy or fitness to undergo curative lung surgery; or once an individual has not smoked for $\geq 15$ years. $^{[12]}$

Both the American Association of Thoracic Surgeons (AATS) and the National Comprehensive Cancer Network (NCCN) have recommended screening for individuals who do not meet NSLT inclusion criteria (younger age and/or lesser smoking exposure), but have an additional risk factor (e.g. asbestos exposure, family history, chronic obstructive pulmonary disease). ${ }^{[19,33]}$ Further studies are needed to better delineate the contribution of these and other risk factors in the development of LC. Potential risk factors that may be particularly relevant in SA and warrant further investigation include: asbestos exposure, silica exposure, HIV infection, and exposure to biomass fuel emissions. Since epidemiological data indicate that HIV-infected individuals have an elevated LC risk independent of smoking, evaluation of the effect of HIV infection on LC development would be informative. ${ }^{[34,35]}$ Similarly, since $\sim 20 \%$ of SA households are exposed to smoke from the burning of solid and biomass fuels, it would be valuable to examine the potential role of biomass fuel emissions in the development of LC in the local population. ${ }^{[36]}$

\section{Potential harmful effects of screening with LDCT}

An ideal LC screening tool provides maximal benefit to the small number of people in whom LC is detected early and treated with surgical resection, without causing harm to the comparatively large number of healthy individuals who undergo screening. While no perfect screening test exists, a good understanding of the potential harmful effects of screening, and discussion of the same, are pivotal in minimising risk and ensuring appropriate and effective implementation of screening programmes. ${ }^{[25]}$

False-positive screens, psychological stress related to fear of having cancer, radiation exposure, incidental findings and overdiagnosis are all potential harmful effects that must be considered when contemplating LC screening. ${ }^{[37]}$

In view of the fact that LDCT scanning does not provide an immediate diagnosis for positive screens, the ability to follow up and appropriately manage pulmonary nodules should be an integral part of any LC screening programme. ${ }^{[24]}$ The RCTs listed in Table 1 all had clearly defined protocols for the identification, reporting and management of pulmonary nodules. There are several society guidelines available to assist in planning nodule management algorithms. Some of these are listed in Table $3 \cdot \cdot^{[19,24,38-40]}$ Detection of false-positive results that require further evaluation occurs in a significant proportion of screened individuals. For example, in the NLST $24.2 \%$ of the LDCT group and $6.9 \%$ of the CXR group had positive screens. However, $96 \%$ of these abnormalities were false-positive findings that did not lead to a diagnosis of cancer. Most positive findings were resolved by serial imaging, but $11 \%$ led to performance of an invasive procedure (1.8\% biopsy, $3.8 \%$ bronchoscopy, $4 \%$ surgical procedure). Although the rate of procedure-related complications was low, it is important to remember that the NLST was conducted in specialist centres, by highly skilled multidisciplinary teams. ${ }^{[16]}$ There are valid concerns as to whether these procedure and complication rates can be reproduced at a community level. In fact, review of the results of the DANTE Trial, which was performed in a community setting, 
suggests that both the rate of invasive procedures and the rate of procedure-related complications were higher than in the NLST. ${ }^{[26]}$

Concerns have been raised regarding the anxiety and psychological distress that may follow a false-positive result. Studies that have evaluated patients' responses to the presence of pulmonary nodules demonstrate that most individuals experience at least mild distress, which may be influenced by the approach of their clinician. ${ }^{[41]}$ However, a systematic review that evaluated the psychosocial effects of LC screening demonstrated that it is associated with only short-term psychological discomfort, and does not affect health-related quality of life or long-term anxiety levels. ${ }^{[42]}$

In the NLST, $8 \%$ of LDCT scans identified clinically significant abnormalities that were unrelated to LC. Such incidental findings may include abnormalities in the lung (e.g. pulmonary fibrosis or emphysema), thyroid and heart; the most common of which is coronary calcification. ${ }^{[43]}$ Currently, the effect of these incidental findings is not well defined, but the potential for their existence should be discussed as part of the decision-making process prior to initiating screening.

\section{Table 1. RCTs evaluating LC screening with LDCT ${ }^{[25]}$}

\begin{tabular}{|c|c|c|c|c|c|c|c|}
\hline & \multicolumn{7}{|c|}{ Trial (lead author) } \\
\hline & $\mathrm{NLST}^{[16]}$ & DANTE $^{[26]}$ & $\operatorname{DLCST}^{[27]}$ & $\mathrm{LUSI}^{[28]}$ & ITALUNG $^{[29]}$ & $\operatorname{MILD}^{[30]}$ & $\mathrm{NELSON}^{[31]}$ \\
\hline Location & USA & Italy & Denmark & Germany & Italy & Italy & $\begin{array}{l}\text { Netherlands and } \\
\text { Belgium }\end{array}$ \\
\hline Sample size & 53454 & 2811 & 4104 & 4052 & 3206 & 4099 & 15822 \\
\hline Sex & $\mathrm{M}, \mathrm{F}$ & M & $\mathrm{M}, \mathrm{F}$ & $\mathrm{M}, \mathrm{F}$ & $\mathrm{M}, \mathrm{F}$ & $\mathrm{M}, \mathrm{F}$ & $\mathrm{M}, \mathrm{F}$ \\
\hline Age (y) & $55-74$ & $60-74$ & $50-70$ & $50-69$ & $55-69$ & $>49$ & $50-75$ \\
\hline $\begin{array}{l}\text { Smoking } \\
\text { history }\end{array}$ & $\begin{array}{l}>30 \text { pack- } \\
\text { years, current } \\
\text { or former } \\
\text { smokers who } \\
\text { have quit } \\
\text { within the } \\
\text { past } 15 \mathrm{y}\end{array}$ & $\begin{array}{l}>20 \text { pack- } \\
\text { years, current } \\
\text { or former } \\
\text { smokers }\end{array}$ & $\begin{array}{l}>20 \text { pack-years, } \\
\text { current or } \\
\text { former smokers } \\
\text { who have quit at } \\
\text { age }>50 \text { y within } \\
\text { the past } 10 \mathrm{y}\end{array}$ & $\begin{array}{l}\text { Current or } \\
\text { former smokers } \\
\text { who quit within } \\
\text { the past } 10 \mathrm{y} \text {; } \\
\text { exposure }>15 \\
\text { cig/d } \times 25 \text { y or } \\
>10 \mathrm{cig} / \mathrm{d} \times 30 \mathrm{y}\end{array}$ & $\begin{array}{l}>20 \text { pack- } \\
\text { years, current } \\
\text { or former } \\
\text { smokers }\end{array}$ & $\begin{array}{l}>20 \text { pack- } \\
\text { years, current } \\
\text { or former } \\
\text { smokers who } \\
\text { have quit } \\
\text { within the } \\
\text { past } 10 \mathrm{y}\end{array}$ & $\begin{array}{l}\text { Current or } \\
\text { former smokers } \\
\text { who quit within } \\
\text { the past } 10 \mathrm{y} ; \\
\text { exposure }>15 \\
\text { cig/d } \times 25 \text { y or } \\
>10 \mathrm{cig} / \mathrm{d} \text { x } 30 \mathrm{y}\end{array}$ \\
\hline $\begin{array}{l}\text { Screening } \\
\text { interval }\end{array}$ & Annual & Annual & Annual & Annual & Annual & $\begin{array}{l}\text { Randomised: } \\
\text { annual or } \\
\text { biennial }\end{array}$ & $\begin{array}{l}\text { Annual, biennial } \\
\text { or every } 30 \\
\text { months }\end{array}$ \\
\hline $\begin{array}{l}\text { Screening } \\
\text { rounds, } n\end{array}$ & 3 & 5 & 5 & 5 & 5 & 5 & 4 \\
\hline $\begin{array}{l}\text { Criteria } \\
\text { for screen- } \\
\text { positive PN }\end{array}$ & $\begin{array}{l}\text { Any diameter } \\
>4 \mathrm{~mm}\end{array}$ & Not specified & $\begin{array}{l}\text { Largest diameter } \\
>5 \mathrm{~mm}\end{array}$ & $\begin{array}{l}\text { Largest diameter } \\
>5 \mathrm{~mm}\end{array}$ & $\begin{array}{l}\text { Largest } \\
\text { diameter } \\
>5 \mathrm{~mm}\end{array}$ & $\begin{array}{l}\text { Volume } \\
>60 \mathrm{~mm}^{3}\end{array}$ & $\begin{array}{l}\text { Volume } \\
>50 \mathrm{~mm}^{3}\end{array}$ \\
\hline
\end{tabular}

Table 2. Professional Societies' Guidelines for LC Screening ${ }^{[25]}$

\begin{tabular}{|c|c|c|}
\hline Society (Reference) & Recommendation & Grade \\
\hline \multirow[t]{3}{*}{$\mathrm{NCCN}^{[19]}$} & Annual LDCT in high-risk individuals & $\mathrm{B}$ \\
\hline & Group 1: age 55 - 79 y with $>30$ pack-years, current or former smokers who quit within the past $15 \mathrm{y}$ & \\
\hline & Group 2: age $>50$ y with $>20$ pack-years and 1 additional risk factor ${ }^{*}$ & \\
\hline $\mathrm{USPSTF}^{[12]}$ & $\begin{array}{l}\text { Annual LDCT in high-risk individuals: age } 55 \text { - } 80 \text { y with }>30 \text { pack-years, current or former smokers who } \\
\text { have quit within the past } 15 \mathrm{y}^{\dagger}\end{array}$ & B \\
\hline $\mathrm{ACCP} / \mathrm{ASCO}^{[17]}$ & $\begin{array}{l}\text { Annual LDCT in high-risk individuals: age } 55-74 \text { y with }>30 \text { pack-years, current or former smokers } \\
\text { who quit within the past } 15 \mathrm{y} \text {, but only in settings that can provide multidisciplinary care similar to that } \\
\text { provided in the NLST }\end{array}$ & $2 \mathrm{~B}$ \\
\hline $\mathrm{ACS}^{[32]}$ & $\begin{array}{l}\text { Annual LDCT in high-risk individuals: age } 55-74 \text { y with }>30 \text { pack-years, current or former smokers who } \\
\text { quit within the past } 15 \mathrm{y} \text {, who are in good health }\end{array}$ & $\mathrm{B}$ \\
\hline \multirow[t]{2}{*}{$\operatorname{AATS}^{[33]}$} & $\begin{array}{l}\text { Annual LDCT in high-risk individuals: age } 55-79 \text { y with }>30 \text { pack-years); individuals aged } 50-79 \text { y with } \\
20 \text { pack-years and added risk of }>5 \% \text { of developing LC in } 5 \mathrm{y}^{\dagger}\end{array}$ & $\mathrm{B}$ \\
\hline & LC survivors in remission $>5 \mathrm{y}$ & $\mathrm{C}$ \\
\hline
\end{tabular}


Overdiagnosis refers to the detection of a cancer that would not otherwise have become clinically relevant during the patient's lifetime. The extended follow-up data for 16 years from the Mayo Lung Project, which demonstrate a persistent excess of cancers in the screened group compared with the control, suggest that overdiagnosis does occur. ${ }^{[4]}$ However, it is uncertain to what extent it occurs in LC screening as reported rates vary widely $(5-51 \%) .{ }^{[45]}$ Although it is a potentially harmful effect of screening, the current estimates available from LDCT trials suggest that the rate of overdiagnosis is relatively low (reported rate in the NLST was $18.5 \%$, or 1.38 cases of overdiagnosis per 320 individuals needed to screen to prevent one LC death). ${ }^{[16]}$ With this in mind, the benefits of screening likely outweigh the risk of overdiagnosis for appropriately selected patients.

Radiation exposure is an inevitable consequence of screening with LDCT. The effective radiation dose from a single LDCT is between 0.61 and $1.5 \mathrm{mSv}$. When compared with other radiological studies, such as a CT pulmonary angiogram $(15 \mathrm{mSv})$ and a routine CT chest $(8 \mathrm{mSv})$ this dose is low. ${ }^{[1846]}$ To date, the only study that has reported exposure related to initial screening and follow-up evaluations is the Italian Lung Study (ITALUNG), which estimated 6 - $7 \mathrm{mSv}$ for a baseline LDCT and three subsequent annual LDCTs. ${ }^{[47]}$ According to the current LC screening recommendations (Table 2), a high-risk patient entering a screening programme at the age of 55 years may undergo 19 annual LDCT scans, with the potential for additional imaging (in the event of a positive screen that requires follow-up), so it is likely that the cumulative radiation risk to the patient may be significantly higher than initial estimates. As always, this potential harmful effect must be tempered with the significant benefits that are to be gained from screening. Based on analysis of available data, one study has suggested that any reduction in excess of $5 \%$ in overall LC mortality would outweigh the radiation risks. ${ }^{[48]}$ This is an area that will require ongoing data collection and regular audit as screening programmes are implemented.

\section{Implementation of LC screening}

Pursuant to the publication of the USPSTF recommendation statement and the various society guidelines (Table 2), several institutions in Europe and the USA are offering screening to

Table 3. Society guidelines for the management of pulmonary nodules ${ }^{[24]}$

\begin{tabular}{lllll}
\hline \multirow{2}{*}{$\begin{array}{l}\text { Nodule } \\
\text { morphology }\end{array}$} & Size $(\mathbf{m m})$ & Fleischner Society ${ }^{[38,39]}$ & NCCN $^{[19]}$ & Lung-RADS \\
\cline { 2 - 4 } Solid & $<6$ & $6-12,18-24^{*}$ & Annual screening & Annual screening \\
& $6-7.9$ & $3-6,9-12,24^{*}$ & 3,6 , annual screening & 6 , annual screening \\
& $8-10$ & $3-6,9-12,24^{*}$ & PET scan and/or biopsy or resect & 3 , annual screening \\
Pure GGN & $\leq 5$ & None & Annual screening & Annual screening \\
& $>5$ & $3,12,24,36$ & 6 , annual screening & Annual screening up to 20 mm \\
Part-solid & $\leq 5$ & 3, then yearly $\times 3$ & Annual screening & Annual screening \\
& $>5$ & 3, then biopsy or resect & As for solid & Based on size of solid component \\
RADS = reporting and data system; PET $=$ positron emission tomography; GGN = ground-glass nodule. &
\end{tabular}

Table 4. Recommended components of a high-quality LDCT LC screening programme ${ }^{[17]}$

\begin{tabular}{|c|c|c|c|c|c|c|c|}
\hline & \multicolumn{7}{|c|}{ Organisation/Society } \\
\hline & $\mathrm{ACCP}^{[24]}$ & $\mathrm{NCCN}^{[19]}$ & USPSTF $^{[12]}$ & $\begin{array}{l}\text { Multisociety } \\
\text { guideline }^{\star 18]}\end{array}$ & $\operatorname{ACS}^{[32]}$ & IASLC $^{[50]}$ & AATS $^{[33}$ \\
\hline \multicolumn{8}{|l|}{ Recommended components } \\
\hline Careful participant selection & Yes & Yes & Yes & Yes & Yes & Yes & Yes \\
\hline Defined screening interval and duration & Yes & Yes & Yes & Yes & Yes & Yes & Yes \\
\hline $\begin{array}{l}\text { Technical specifications and quality controls for } \\
\text { performance of LDCT scan }\end{array}$ & Yes & Yes & Yes & Yes & Yes & Yes & Yes \\
\hline Positive screen criteria for PNs & Yes & Yes & Yes & Yes & Yes & Yes & - \\
\hline Structured LDCT reporting & Yes & Yes & Yes & Yes & Yes & Yes & - \\
\hline $\begin{array}{l}\text { PN management algorithm with a multi- } \\
\text { disciplinary team }\end{array}$ & Yes & Yes & Yes & Yes & Yes & Yes & Yes \\
\hline Smoking cessation & Yes & Yes & Yes & Yes & Yes & Yes & Yes \\
\hline Patient and provider education & Yes & Yes & Yes & Yes & Yes & - & - \\
\hline Data collection & Yes & Yes & Yes & Yes & - & Yes & Yes \\
\hline
\end{tabular}


high-risk individuals. However, there remain concerns about the generalisability of the NLST findings to scenarios outside the tertiary-care setting. When compared with the high-risk US population that is currently being offered screening, the population in the NLST differed in several respects. The participants were younger, had a higher level of education and were more likely to be former smokers. ${ }^{[49]}$ In addition, of the 33 centres involved in the study the majority were tertiary-care academic facilities that were designated National Cancer Institute (NCI) cancer centres. The level of multidisciplinary expertise available at the trial centres likely accounts for the low rate of invasive procedures undertaken to follow-up positive screen results, as well as for the low mortality rate for surgical resection ( $1 \%$ as compared with $4 \%$ previously reported in the US general population). ${ }^{[16]}$

Guidelines and policy statements from various international professional societies have recognised that a multidisciplinary team, of a similar calibre to those that participated in the NLST, is a necessity if the outcomes of the NLST are to be replicated in clinical practice. Furthermore, they have highlighted the point that LC screening, if not conducted properly, is potentially harmful. ${ }^{[16,18]}$ It is for this reason that there has been much focus on identifying the components that are necessary in order to implement a high-quality, safe and effective screening programme. Table 4 lists the components recommended by the different professional societies to guide LC screening in the community. ${ }^{[12,17-19,24,32,33,50]}$

\section{Risk assessment and communication of risk}

Several accurate and efficient risk stratification models have been developed to assist in determining an individual's risk for LC (Table 5).$^{[20,51-54]}$ Although these prediction models were designed with a research setting in mind, none of the RCTs listed in Table 1 made use of these models to define their entry criteria. Despite the fact that these risk-prediction models were developed primarily as research tools, they do have utility in clinical practice. They can be used as information and discussion tools for patient consultations and they may assist patients in understanding their own individual risk for LC. This is a vital component of the screening process as patient understanding and participation in making decisions regarding participation (or not) are vital to the successful implementation of any screening programme. ${ }^{[34]}$

\section{Importance of smoking cessation}

Although there are a number of environmental risk factors that are associated with LC development, there is strong evidence that cigarette smoking, which is considered to be causal in $\sim 85-90 \%$ of cases, is the primary risk factor. ${ }^{[55]}$ Even among non-smokers, a proportion of LC cases are thought to be attributable to second-hand tobacco smoke exposure. ${ }^{[56]}$ The risk of developing LC rises with increasing cumulative tobacco smoke exposure. ${ }^{[12]}$ However, some studies suggest that, for a given level of smoking exposure, women are at higher risk of developing cancer than men. ${ }^{[57,58]}$ Since the risk for LC only declines many years after smoking cessation, it is also important to recognise that a significant percentage of LCs occur in former smokers. ${ }^{[59-61]}$

Since cigarette smoking plays a central role in LC development, promotion of smoking cessation and reduction in population smoking rates are imperative for reducing the long-term burden of disease and cannot be replaced by LC screening. The decline in LC incidence and mortality among men in the US between 1975 and 2010 , which was observed in tandem with a reduction in the smoking rate among adults in the US between 1965 and 2011, lends support to smoking cessation as an effective means of lowering LC mortality. ${ }^{[1,62]}$

Available evidence suggests that LDCT screening itself does not influence smoking behaviour and that despite enrolment in LC screening trials and increased awareness, some participants continue to smoke. ${ }^{[63]}$ Those individuals who had a positive screen test for LC have been shown to have a $6 \%$ lower rate of smoking compared with those who had normal screens. ${ }^{[64]}$ Not only is smoking cessation and LC prevention more effective than screening in lowering LC mortality, but it is also a much more cost-effective strategy. ${ }^{[24,65]}$

\section{Cost of LDCT screening}

Following the USPSTF's publication of a grade B recommendation in favour of implementation of LDCT screening for high-risk individuals in $2014,{ }^{[12]}$ and after considering the guidelines and position papers of several major medical societies (Table 2), US healthcare funders agreed to fund LC screening with LDCT, at approved LC screening centres, for individuals who meet NLST eligibility.

In light of the large number of patients who may qualify for annual screening, based on the specified criteria, it is reasonable to expect that the costs may be considerable. Therefore, one of the major

Table 5. LC Risk prediction models

\begin{tabular}{|c|c|c|c|c|c|}
\hline & \multicolumn{5}{|c|}{ Model } \\
\hline & $\operatorname{Bach}^{[51]}$ & Spitz $^{[52]}$ & Liverpool Lung Project ${ }^{[53]}$ & Hoggart $^{[54]}$ & Modified PLCO ${ }_{\mathrm{M} 2012}{ }^{[20]}$ \\
\hline Age (y) & $50-75$ & $20-80$ & $20-80$ & $35-65$ & $55-74$ \\
\hline \multirow[t]{7}{*}{ Variables } & Age & Age & Age & Age & Age \\
\hline & Smoking & Smoking & Smoking & Smoking & Smoking \\
\hline & Sex & Sex & Sex & & BMI \\
\hline & Asbestos & Dust & Asbestos & & COPD \\
\hline & & Emphysema & Family history & & CXR \\
\hline & & Family history & Pneumonia & & Family history \\
\hline & & & Prior cancer & & Education \\
\hline
\end{tabular}


considerations for policymakers in the US has been the cost and cost-effectiveness of LDCT screening. ${ }^{[66]}$ In order to address some of the questions around cost-efficacy, Black et al. ${ }^{[67]}$ examined the costs of LDCT screening in the NLST, estimating mean life-years, qualityadjusted life-years (QALYs), costs per person and incremental costeffectiveness ratios (ICERs) for three categories: LDCT screening, screening with CXR and no screening. According to their analysis, the cost of CT screening per QALY gained was USD81 000. However, they also noted that the ICERs varied widely in subgroup and sensitivity analyses, suggesting that modest changes in certain study assumptions could greatly alter the estimated figure. Ultimately, they concluded that cost efficacy of LC screening outside the NLST setting will depend on how the programmes are implemented at the community level.

Local data regarding the costs involved in LC screening are lacking for both the public and private sector. Currently, many private radiology practices do not have a specific fee structure in place for LDCT screening. However, those that do, report a cost of ZAR2 600 - 3800 per screening test, inclusive of consultation with a physician. As this fee is not covered by most SA medical aid funds at present, this cost is borne by the patient (direct correspondence, private hospitals in Johannesburg, October 2015). Further research and data collection in this area are required before a dialogue between the relevant roleplayers can be held. Unfortunately, given the existing strains on an already over-burdened public healthcare system, and resistance on the part of private healthcare funders to pay for screening in the private sector, LC screening will most likely only be accessible to a small minority of SA citizens for the foreseeable future.

\section{Conclusion}

LC is a deadly malignancy. Until recently, there was no proven method for early detection, but with the advent of LDCT screening, there is the potential to save lives in high-risk individuals by detecting and treating early-stage disease. However, the false-positive rate for LC screening is high and the potential benefits may be diminished if screening results in increased morbidity and mortality related to increased frequency of invasive procedures. Refinement of eligibility criteria and the use of structured, standardised reporting for CT interpretation may mitigate risk by reducing the number of false-positives identified on screening. A well-defined protocol for management of screen-detected pulmonary nodules is a vital component of any LC screening programme and may aid in minimising unnecessary surgery.

Successful implementation of LC screening relies on a comprehensive, multidisciplinary programme with an emphasis on smoking cessation and LC prevention. Balanced presentation of potential benefits, harms and costs of screening, such that individuals are able to make informed decisions about their healthcare choices, is of the utmost importance and risk-prediction models may be of use in facilitating these discussions.

In SA we face unique challenges in implementing LC screening. Identification of risk factors that are particularly relevant to our local population (e.g. HIV infection, silica exposure and biomass emissions exposure) is an area where future research is required. Limited resources in the state sector and restricted funding by medical aids in the private sector both pose significant barriers to the equitable implementation of LC screening in our communities. Collation of comprehensive local LC data and engaging the relevant role-players in discussion will be important initial steps towards planning a LC screening programme in the local setting.

\section{References}

1. Ferlay J, Soerjomataram I, Ervik M, et al. GLOBOCAN 2012 v1.0, Cancer Incidence and Mortality Worldwide: IARC Cancer Base No.11. Lyon, France: International Agency for Research on Cancer, 2013. http://globocan.iarc.fr. (accessed 2 September 2015).

2. Global Burden of Disease Cancer Collaboration, Fitzmaurice C, Dicker D, et al. The Global Burden of Cancer 2013. JAMA Oncol 2015;1(4):505-527. [http://dx.doi.org/ 10.1001/jamaoncol.2015.0735]

3. Siegel R, Naishadham D, Jemal A. Cancer statistics, 2012. CA Cancer J Clin 2012;62(1):10-29. [http://dx.doi.org/10.3322/caac.20138]

4. Wilcox PA, O'Brien JA, Abratt RP. Lung cancer at Groote Schuur Hospital: A local perspective. S Afr Med J 1990;78(12):716-720.

5. Howlader N, Noone AM, Krapcho M, et al. (eds). SEER Cancer Statistics Review, 1975 - 2011 [based on the November 2013 SEER data submission, posted to the SEER website April 2014]. Bethesda, USA: National Cancer Institute, 2014.

6. Mountain CF. Revisions in the International System for Staging Lung Cancer. Chest 1997;111(6):1710-1717.

7. Flieder DB, Port JL, Korst RJ, et al. Tumor size is a determinant of stage distribution in T1 non-small cell lung cancer. Chest 2005;128(4):2304-2308. [http://dx.doi. org/10.1378/chest.128.4.2304]

8. Deffebach ME, Humphrey L. Screening for lung cancer. http://uptodate.com (accessed 5 August 2015).

9. Siegal R, Ward E, Brawley O, Jemal A. Cancer statistics, 2011: The impact of eliminating socio-economic and racial disparities on premature cancer deaths. CA Cancer J Clin 2011;61(4):212-236. [http://dx.doi.org/10.3322/caac.20121]

10. Jett JR. Current treatment of unresectable lung cancer. Mayo Clinic Proc 1993;68(6):603-611.

11. Mukansi M, Smith C, Feldman C. A study of lung cancer in Johannesburg, South Africa. South Afr J Infect Dis 2013;29(1):43-47. [http://dx.doi.org/10.1080/231200 53.2014.11441566]

12. Moyer VA. Screening for lung cancer: US Preventative Services Task Force recommendation statement. Ann Intern Med 2014;160(5):330-338. [http://dx.doi. org/10.7326/M13-2771]

13. Oken MM, Hocking WG, Kvale PA, et al. Screening by chest radiograph and lung cancer mortality: The Prostate, Lung, Colorectal, and Ovarian (PLCO) randomised trial. JAMA 2011;306(17):1865-1873. [http://dx.doi.org/10.1001/jama.2011.1591]

14. Fontana RS, Sanderson DR, Taylor WF, et al. Early lung cancer detection: Results of the initial (prevalence) radiologic and cytologic screening in the Mayo Clinic study. Am Rev Resp Dis 1984;130(4):561-565.

15. Henschke CI, McCauley DI, Yankelevitz DF, et al. Early Lung Cancer Action Project: Overall design and findings from baseline screening. Lancet 1999;354(9173):99-105. [http://dx.doi.org/10.1016/S0140-6736(99)06093-6]

16. Aberle DR, Adams AM, Berg CD, et al. Reduced lung cancer mortality with low-dose computed tomographic screening. N Engl J Med 2011;365(5):395-409. [http://dx.doi. org/10.1056/NEJMoa1102873]

17. Detterbeck FC, Mazzone PJ, Naidich DP, Bach PB. Screening for lung cancer. Diagnosis and management of lung cancer, 3rd ed. American College of Chest Physicians evidence-based clinical practice guidelines. Chest 2013;143(5 Suppl):e78Se92S. [http://dx.doi.org/10.1378/chest.12-2350]

18. Bach PB, Mirkin JN, Oliver TK, et al. Benefits and harms of CT screening for lung cancer: A systematic review. JAMA 2012;307(22):2418-2429. [http://dx.doi. org/10.1001/jama.2012.5521]

19. National Comprehensive Cancer Network. Lung Cancer Screening. http://www.nccn. org/professionals/physician_gls/f_guidelines.asp (accessed 12 August 2015).

20. Tammemägi MC, Katki HA, Hocking WG, et al. Selection criteria for lungcancer screening. N Engl J Med 2013;368(8):728-736. [http://dx.doi.org/10.1056/ NEJMoa1211776]

21. Kovalchik SA, Tammemagi MC, Berg CD, et al. Targeting of low-dose CT screening according to the risk of lung-cancer death. N Engl J Med 2014;369(3):245-254. [http:// dx.doi.org/10.1056/NEJMoa1301851]

22. de Koning HJ, Meza R, Plevritis SK, et al. Benefits and harms of computed tomography lung cancer screening strategies: A comparative modeling study for the US Preventative Task Force. Ann Intern Med 2014;160(5):311-320. [http://dx.doi. org/10.7326/M13-2316]

23. Peto R, Darby S, Deo H, Silcocks P, Whiteley E, Doll R. Smoking, smoking cessation, and lung cancer in the UK since 1950: Combination of national statistics with two case-control studies. BMJ 2000;321(7527):323-329. [http://dx.doi.org/10.1136/ bmj.321.7257.323] 
24. Mazzone P, Powell CA, Arenberg D, et al. Components necessary for high-quality lung cancer screening. Chest 2015;147(2):295-303. [http://dx.doi.org/10.1378/ chest.14-2500]

25. Kandora NM, Silvestri GA, Tanner NT. Screening and early detection efforts in lung cancer. Cancer 2015;121(9):1347-1356. [http://dx.doi.org/10.1002/cncr.29222]

26. Infante M, Cavuto S, Lutman FR, et al. Long-term follow-up results of the DANTE trial, a randomised study of lung cancer screening with spiral computed tomography. Am J Respir Crit Care Med 2015;191(10):1166-1175. [http://dx.doi.org/10.1164/ rccm.201408-1475OC]

27. Saghir Z, Dirksen A, Ashraf H, et al. CT screening for lung cancer brings forward early disease. The randomised Danish Lung Cancer Screening Trial: Status after 5 annual screening rounds with low-dose CT. Thorax 2012;67(4):296-301. [http:// dx.doi.org/10.1136/thoraxjnl-2011-200736]

28. Becker N, Motsch E, Gross ML, et al. Randomized study on early detection of lung cancer with MSCT in Germany: Study design and results of the first screening round. J Cancer Res Clin Oncol 2012;138(9):1475-1486. [http://dx.doi.org/10.1007/s00432012-1228-9]

29. Lopes Pegna A, Picozzi G, Falaschi F, et al. ITALUNG Study Research Group. Fouryear results of low-dose CT screening and nodule management in the ITALUNG trial. J Thorac Oncol 2013;8(7):866-875. [http://dx.doi.org/10.1097/JTO.0b013e31828f68d6]

30. Pastorino U, Rossi M, Rosato V, et al. Annual or biennial CT screening versus observation in heavy smokers: 5-year results of the MILD trial. Eur J Cancer Prev 2012;21(3):308-315. [http://dx.doi.org/10.1097/CEJ.0b013e328351elb6]

31. Horeweg N, van der Aalst CM, Vliegenthart R, et al. Volumetric computed tomography screening for lung cancer: 3 rounds of the NELSON trial. Eur Resp J 2013;42(6):16591677. [http://dx.doi.org/10.1183/09031936.00197712]

32. Wender R, Fontham ET, Barrera E Jr, et al. American Cancer Society lung cancer screening guidelines. CA Cancer J Clin 2013;63(2):107-117. [http://dx.doi. org/10.3322/caac.21172]

33. Jaklitsch MT, Jacobson FL, Austin JHM, et al. The American Association for Thoracic Surgery guidelines for lung cancer screening using low-dose computed tomography scans for cancer survivors and other high risk groups. J Thorax Cardiovasc Surg 2012;144(1):33-38. [http://dx.doi.org/10.1016/j.jtcvs.2012.05.060]

34. Mani H, Halgentz Jr M, Aboulafia DM. Lung cancer in HIV infection. Clin Lung Cancer 2012;13(1):6-13. [http://dx.doi.org/10.1016/j.cllc.2011.05.005]

35. Winstone TA, Man SF, Hull M, et al. Epidemic of lung cancer in patients with HIV. Chest 2013;143(2):305-314. [http://dx.doi.org/10.1378/chest.12-1699]

36. Norman R, Barnes B, Mathee AM, Bradshaw D, and the South African Comparative Risk Assessment Collaborating Group. Estimating the burden of disease attributable to indoor air pollution from household use of solid fuels in South Africa in 2000. S Afr Med J 2007;97(8):764-771.

37. Humphrey L, Deffebach M, Pappas M, et al. Screening for lung cancer with low-dose computed tomography: A systematic review to update the US Preventative Services Task Force recommendation. Ann Intern Med 2013;159(6):411-420. [http://dx.doi. org/10.7326/0003-4819-159-6-201309170-00690]

38. MacMahon H, Austin JHM, Gamsu G, et al. Fleischner Society. Guidelines for management of small pulmonary nodules detected on CT scans: A statement from the Fleischner Society. Radiology 2005;237(2):395-400. [http://dx.doi.org/10.1148/ radiol.2372041887]

39. Naidich DP, Bankier AA, MacMahon $\mathrm{H}$, et al. Recommendations for the management of subsolid pulmonary nodules detected at CT: A statement from the Fleischner Society. Radiology 2013;266(1):304-317. [http://dx.doi.org/10.1148/ radiol.12120628

40. American College of Radiology. Lung CT Screening Reporting and Data System (Lung-RADS). http://www.acr.org/ /media/ACR/Documents/PDF/QualitySafety/ Resources/LungRADS/AssessmentCategories.pdf (accessed 9 September 2015).

41. Slatore CG, Press N, Au DH, Curtis JR, Wiener RS, Ganzini L. What the heck is a "nodule"? A qualitative study of veterans with pulmonary nodules. Ann Am Thorac Soc 2013;10(4):330-335. [http://dx.doi.org/10.1513/AnnalsATS.201304-080OC]

42. Slatore CG, Sullivan DR, Pappas M, Humphrey LL. Patient-centred outcomes among lung cancer screening recipients with computed tomography: A systematic review. J Thorac Oncol 2014;9(7):927-934. [http://dx.doi.org/10.1097/JTO.0000000000000210]

43. Kucharczyk MJ, Menezes RJ, McGregor A, Paul NS, Roberts HC. Assessing the impact of incidental findings in a lung cancer screening study by low-dose computed tomography. Can Assoc Radiol J 2011;62(2):141-145. [http://dx.doi.org/10.1016/j. carj.2010.02.008
44. Marcus PM, Bergstralh EJ, Zweig MH, Harris A, Offord KP, Fontana RS. Extended lung cancer incidence follow-up in the Mayo Lung Project and overdiagnosis. J Nat Cancer Inst 2006;98(11):748-756. [http://dx.doi.org/10.1093/jnci/djj207]

45. Yankelevitz DF, Kostis WJ, Henschke CI, et al. Overdiagnosis in chest radiographic screening for lung carcinoma: Frequency. Cancer 2003;97(5):1271-1275. [http:// dx.doi.org/10.1002/cncr.11185]

46. Smith-Bindman R, Lipson J, Marcus R, et al. Radiation dose associated with common computed tomography examinations and the associated lifetime attributable risk of cancer. Arch Intern Med 2009;169(22):2078-2086. [http://dx.doi.org/10.1001/ archinternmed.2009.427]

47. Mascalchi M, Mazzoni LN, Falchini M, et al. Dose exposure in the ITALUNG trial of lung cancer screening with low-dose CT. Br J Radiol 2012;85(1016):1134-1139. [http://dx.doi.org/10.1259/bjr/20711289]

48. Brenner DJ. Radiation risks potentially associated with low-dose CT screening of adult smokers for lung cancer. Radiology 2004;231(2):440-445. [http://dx.doi.org/10.1148/ radiol.2312030880]

49. National Lung Screening Trial Research Team, Aberle DR, Adams AM, Berg CD, et al. Baseline characteristics of participants in the randomised national lung screening trial. J Natl Cancer Inst 2010;102(23):1771-1779. [http://dx.doi.org/10.1093/jnci/djq434]

50. Field JK, Smith RA, Aberle DR, et al. IASLC CT Screening Workshop 2011 Participants. International Association for the Study of Lung Cancer Computed Tomography Screening Workshop 2011 report. J Thorac Oncol 2012;7(1):10-19. [http://dx.doi.org/10.1097/JTO.0b013e31823c58ab]

51. Bach PB, Kattan MW, Thornquist MD, et al. Variations in lung cancer risk among smokers. J Natl Cancer Inst 2003;95(6):470-478. [http://dx.doi.org/10.1093/jnci/95.6.470]

52. Spitz MR, Hong WK, Amos CI, et al. A risk model for prediction of lung cancer. J Natl Cancer Inst 2007;99(9):715-726. [http://dx.doi.org/10.1093/jnci/djk153]

53. Cassidy A, Myles JP, van Tongeren M, et al. The LLP risk model: An individual risk prediction model for lung cancer. Br J Cancer 2008;98(2):270-276. [http://dx.doi. org/10.1038/sj.bjc.6604158]

54. Hoggart C, Brennan P, Tjonneland A, et al. A risk model for lung cancer incidence. Cancer Prev Res (Phila) 2012;5(6):834-846. [http://dx.doi.org/10.1158/1940-6207. CAPR-11-0237]

55. Alberg AJ, Samet JM. Epidemiology of lung cancer. Chest 2003;123(1 Suppl):21S-49S.

56. Fontham ET, Correa P, Reynolds P, et al. Environmental tobacco smoke and lung cancer in non-smoking women. A multicentre study. JAMA 1994;271(22):1752-1759.

57. McDuffie HH, Klaassen DJ, Dosman JA. Men, women and primary lung cancer - a Saskatchewan personal interview study. J Clin Epidemiol 1991;44(6):537-544.

58. Osann KE, Anton-Culver H, Kurosaki T, Taylor T. Sex differences in lung-cancer risk associated with cigarette smoking. Int J Cancer 1993;54(1):44-48.

59. Burns DM. Primary prevention, smoking, and smoking cessation: Implications for future trends in lung cancer prevention. Cancer 2000;89(11 Suppl):2506-2509.

60. Halpern MT, Gillespie BW, Warner KE. Patterns of absolute risk of lung cancer mortality in former smokers. J Natl Cancer Inst 1993;85(6):457-464.

61. Tong L, Spitz MR, Fueger JJ, Amos CA. Lung carcinoma in former smokers. Cancer 1996;78(5):1004-1010.

62. Office on Smoking and Health, Centers for Disease Control and Prevention. Trends in current cigarette smoking among high school students and adults, United States, 1965 - 2011. http://www.cdc.gov/tobacco/data_statistics/tables/trends/cig_smoking/ (accessed 3 September 2015).

63. Slatore CG, Baumann C, Pappas M, Humphrey LL. Smoking behaviors among patients receiving computed tomography for lung cancer screening. Systematic review in support of the US Preventative Services Task Force. Ann Am Thorac Soc 2014;11(4):619-627. [http://dx.doi.org/10.1513/AnnalsATS.201312-460OC]

64. Tammemägi MC, Berg CD, Riley TL, Cunningham CR, Taylor KL. Impact of lung cancer screening results on smoking cessation. J Natl Cancer Inst 2014;106(6):dju084. [http://dx.doi.org/10.1093/jnci/dju084]

65. Villanti AC, Jiang Y, Abrams DB, Pyenson BS. A cost-utility analysis of lung cancer screening and the additional benefits of incorporating smoking cessation interventions. PLoS One 2013;8(8):e71379. [http://dx.doi.org/10.1371/journal. pone.0071379]

66. Sox HC. Better evidence about screening for lung cancer. N Engl J Med 2011;365(5):455-457. [http://dx.doi.org/10.1056/NEJMe1103776]

67. Black WC, Gareen IF, Samir SS, et al. Cost-effectiveness of CT screening in the National Lung Screening Trial. N Engl J Med 2014;371(19):1793-1802. [http://dx.doi. org/10.1056/NEJMoa1312547] 